\title{
AJUSTAMENTO INTERCULTURAL DE EXECUTIVOS JAPONESES EXPATRIADOS NO BRASIL: UM ESTUDO EMPÍRICO
}

\author{
INTERCULTURAL ADJUSTMENT OF JAPANESE EXPATRIATE EXECUTIVES IN BRAZIL: AN \\ EMPIRICAL STUDY
}

AJUSTE INTERCULTURAL DE EJECUTIVOS JAPONESES EXPATRIADOS EN BRASIL: UN ESTUDIO EMPÍRICO

\section{RESUMO}

O ajustamento intercultural tem sido considerado fator determinante do sucesso em missões internacionais e o conceito-chave do modelo de ajustamento internacional de Black, Mendenhall e Oddou (1991a). O objetivo deste artigo é analisar o ajustamento intercultural de executivos japoneses expatriados. Realizou-se uma pesquisa qualitativa com 37 executivos japoneses expatriados, em $21 \mathrm{em}-$ presas de diversos setores no Brasil. Apesar de a literatura considerar os expatriados japoneses exemplos de sucesso, devido às baixas taxas de falhas em missões internacionais, os resultados mostram que eles não se ajustam, pois recebem pouco ou nenhum treinamento intercultural, permanecem distantes dos locais, além de acumularem estresse no trabalho e não poderem falhar. Este artigo contribui para o melhor entendimento do construto do ajustamento intercultural e reforça a necessidade de rever o modelo de Black, Mendenhall e Oddou (1991a) para outras nacionalidades.

PALAVRAS-CHAVE Expatriação, ajustamento intercultural, expatriados japoneses, missão internacional, gestão internacional de pessoas.

Edson Keyso de Miranda Kubo edsonkubo@gvmail.br

Professor do Programa de Pós-Graduação em Administração, Universidade Municipal de São Caetano do Sul - São Caetano do Sul - SP, Brasil

Beatriz Maria Braga beatriz.braga@fgv.br

Professora da Escola de Administração de Empresas de São Paulo, Fundação Getulio Vargas - São Paulo - SP, Brasil

\begin{abstract}
Intercultural adjustment has been considered a determinant factor of success in international assignments and the key concept of the model of international adjustment from Black, Mendenhall and Oddou (1991a). The objective of this article is to analyze how intercultural adjustment occurs among Japanese expatriate executives. A qualitative research was conducted with 37 Japanese expatriate executives in Brazil from 21 different subsidiaries in various sectors. Although the literature considers Japanese expatriates as examples of success due to their low failure rates in international assignments, the results shows that they do not adjust, because they receive little or neither intercultural training, keep distance from locals, and feel a lot of stress on work and cannot fail. This article contributes to a better understanding of the construct of intercultural adjustment and emphasizes the need to revise the model of Black, Mendenhall and Oddou (1991a) for other nationalities.

keywords Expatriation, intercultural adjustment, japanese expatriates, international assignment, international human resource management.

Resumen El ajuste intercultural ha sido considerado un factor determinante del éxito en misiones internacionales y el concepto clave del modelo de ajuste internacional de Black, Mendenhall y Oddou (1991a). El objetivo de este artículo es analizar el ajuste intercultural de ejecutivos japoneses expatriados. Se realizó una investigación cualitativa con 37 ejecutivos japoneses expatriados, en 21 empresas de diversos sectores en Brasil. A pesar de que la literatura considera a los expatriados japoneses como ejemplos de éxito, debido a las bajas tasas de fallas en misiones internacionales, los resultados muestran que ellos no se ajustan, pues reciben poco o ningún entrenamiento intercultural, permanecen distantes de los lugares, además de acumular estrés en el trabajo sin poder fallar. Este artículo contribuye a una mejor comprensión del constructo del ajuste intercultural y refuerza la necesidad de rever el modelo de Black, Mendenhall y Oddou (1991a) para las otras nacionalidades.
\end{abstract}

Palabras clave Expatriación, ajuste intercultural, expatriados japoneses, misión internacional, gestión internacional de personas. 


\section{INTRODUÇÃO}

Em Gestão Internacional de Pessoas (GIP), os temas da expatriação e do ajustamento têm sido objeto de grande número de pesquisas nas últimas décadas. Pressuposto fundamental é o de que o ajustamento do expatriado é essencial para que a designação internacional seja bem-sucedida, o que terá impacto direto sobre o desempenho da subsidiária e a organização (BJORKMAN e STAHL, 2006; HOMEM e TOLFO, 2008). Nos estudos de expatriação, o modelo de ajustamento internacional de Black, Mendenhall e Oddou (1991a) tem sido a principal referência para pesquisas empíricas sobre ajustamento e políticas de expatriação, sendo amplamente utilizado para formulação de políticas de staffing (STAHL e CALIGIURI, 2005).

De acordo com esse modelo, cabe ao expatriado desenvolver sua familiaridade e conforto com os vários aspectos do ambiente intercultural do país anfitrião, pois, sem esse ajustamento, não há como se obter sucesso na expatriação. E a falha na expatriação, tradicionalmente conceituada na literatura como a volta prematura do expatriado (TUNG, 1987), representa, para a empresa, um custo elevado não apenas em termos financeiros mas também em termos do conhecimento e rede de relacionamento adquiridos pelo indivíduo (LEE, 2007).

No entanto, o caso dos japoneses parece contradizer o pressuposto de que o ajustamento intercultural é necessário para que o expatriado seja bem-sucedido. Isso porque, por um lado, pesquisas apontam que as estratégias de expatriação das empresas multinacionais japonesas (EMJ) apresentam taxas menores de falhas quando comparadas com as das multinacionais americanas, e são apresentadas mundialmente como casos de sucesso (TUNGLI e PEIPERL, 2009). Por outro lado, algumas pesquisas mostram que os japoneses não estão preocupados com o ajustamento ao país anfitrião, não convivem com os "locais", como se referem aos nativos do país anfitrião (HOMEM e TOLFO, 2008, p. 206), e não se preocupam em assimilar aspectos da cultura organizacional da subsidiária (JAPAN OVERSEAS ENTERPRISES ASSOCIATION, 2007).

Este artigo analisa o ajustamento intercultural dos executivos expatriados japoneses no Brasil - se e como o expatriado se ajusta - fornecendo subsídios para a compreensão do fenômeno do ajustamento e complementando o entendimento atual sobre o tema, em grande parte, fundamentado em pesquisas com expatriados norte-americanos (YAMAZAKI e KAYES, 2007).

\section{AJUSTAMENTO INTERCULTURAL DOS EXPATRIADOS: 0 MODELO DE BLACK, MENDENHALL E ODDOU (1991a)}

Entende-se por expatriado o executivo enviado por uma multinacional para viver e trabalhar em um país estrangeiro por período superior a um ano (CALIGIURI, 2000). O ajustamento intercultural dos expatriados tem sido definido de diversas maneiras (ANDREASON, 2003; AYCAN, 1997; BLACK, MENDENHALL, ODDOU, 1991b; NICHOLSON e IMAIZUMI, 1993). A proposição de Oberg (1960) define ajustamento intercultural como o grau de conforto psicológico com vários aspectos do país anfitrião. De acordo com Winkelman (1994), o conforto psicológico é a sensação de bem-estar que propicia autoestima e satisfação em relação à vida. Sem o conforto psicológico, a pessoa experimenta uma deterioração no seu senso de bem-estar, o que resulta em manifestações patológicas tais como desordem emocional, irritabilidade e hostilidade. No caso da expatriação, a falta de conforto psicológico traria mau ajustamento, que seria a causa principal das falhas ocorridas.

Grande parte dos estudos sobre o ajustamento na expatriação toma por base teórica o modelo internacional de Black, Mendenhall e Oddou (1991a), que propõe que o ajustamento deveria ocorrer em dois momentos: o antecipado, ainda no país de origem, e o ajustamento no país anfitrião.

O ajustamento antecipado é composto de fatores anteriores à expatriação que facilitariam o ajustamento no país anfitrião, tais como a seleção de candidatos com base em competências interculturais (e não apenas nas competências técnicas) e a preparação em geral do candidato antes de sua partida, por meio de treinamentos interculturais e fornecimento de informações sobre o país anfitrião.

Os autores propõem que o ajustamento no país anfitrião seja formado por três componentes; dessa maneira, os expatriados precisam atender às dimensões de ajustamento geral (conforto com vários aspectos do ambiente geral do país anfitrião, tais como costumes, vida cotidiana etc.), ajustamento interacional (conforto e familiaridade no relacionamento com os locais) e ajustamento no trabalho (conforto em relação ao trabalho desenvolvido com os locais). Segundo os autores, o ajustamento nessas três dimensões seria fundamental para que o expatriado pudesse desempenhar bem suas funções e ser bem-sucedido em sua missão internacional. 
O modelo prevê alguns outros fatores que também influenciam as dimensões do ajustamento:

i. fatores individuais, como a autoeficácia do expatriado, ao manifestar suas habilidades de persistir na exibição de comportamentos aprendidos no país anfitrião para receber feedback dos locais; a habilidade de desenvolver relacionamento com locais; e habilidades cognitivas que permitam ao expatriado perceber corretamente o ambiente local e seus atores;

ii. o trabalho em si, que deveria ser claramente definido, com um grau de autonomia que permita ao expatriado a compreensão de seus papéis gerenciais e poder decisório para adaptar as funções e condições do trabalho local de acordo com suas expectativas. Ainda em relação ao trabalho, deve-se observar a novidade da função (grau de diferença entre o trabalho local e o trabalho anterior do expatriado) e o conflito da função (choques de demandas entre a matriz e a subsidiária no que tange o trabalho do expatriado), que estariam negativamente associados ao ajustamento no trabalho;

iii. a cultura organizacional, que contempla a diferença entre a cultura organizacional da subsidiária e a cultura da matriz (novidade da cultura), o apoio dos colegas e superiores no país anfitrião (apoio social) e a ajuda logística, que se refere ao suporte quanto à moradia, compras, escolas etc;

iv. a socialização na empresa local, que seria baseada em táticas institucionais (conteúdo preparado pela instituição) ou táticas individuais (atitude individual em aprender e inovar em suas funções no trabalho) e

v. os itens não relacionados ao trabalho, que seriam a novidade da cultura local e o ajustamento da família, em especial o cônjuge. O modelo está sintetizado na Figura 1 a seguir:

Shaffer, Harrison e Gilley (1999), Stroh, Dennis e Cramer (1994), Shay e Baack (2006) são alguns dos estudos que testaram e validaram o modelo de Black, Mendenhall e Oddou (1991a), acrescentando variáveis como a habilidade em falar línguas estrangeiras e a vontade do expatriado de completar a missão. Outros estudos, no entanto, como Aycan (1997), Andreason (2003) e Harrison e Shaffer (2005), obtiveram diferentes graus de confirmação das relações propostas. Esses estudos, de maneira geral, partem do pressuposto de que, sem o ajustamento do expatriado, não haveria sucesso na expatriação.

O caso dos expatriados japoneses parece singular,

\section{Figura 1 - O modelo de ajustamento internacional}

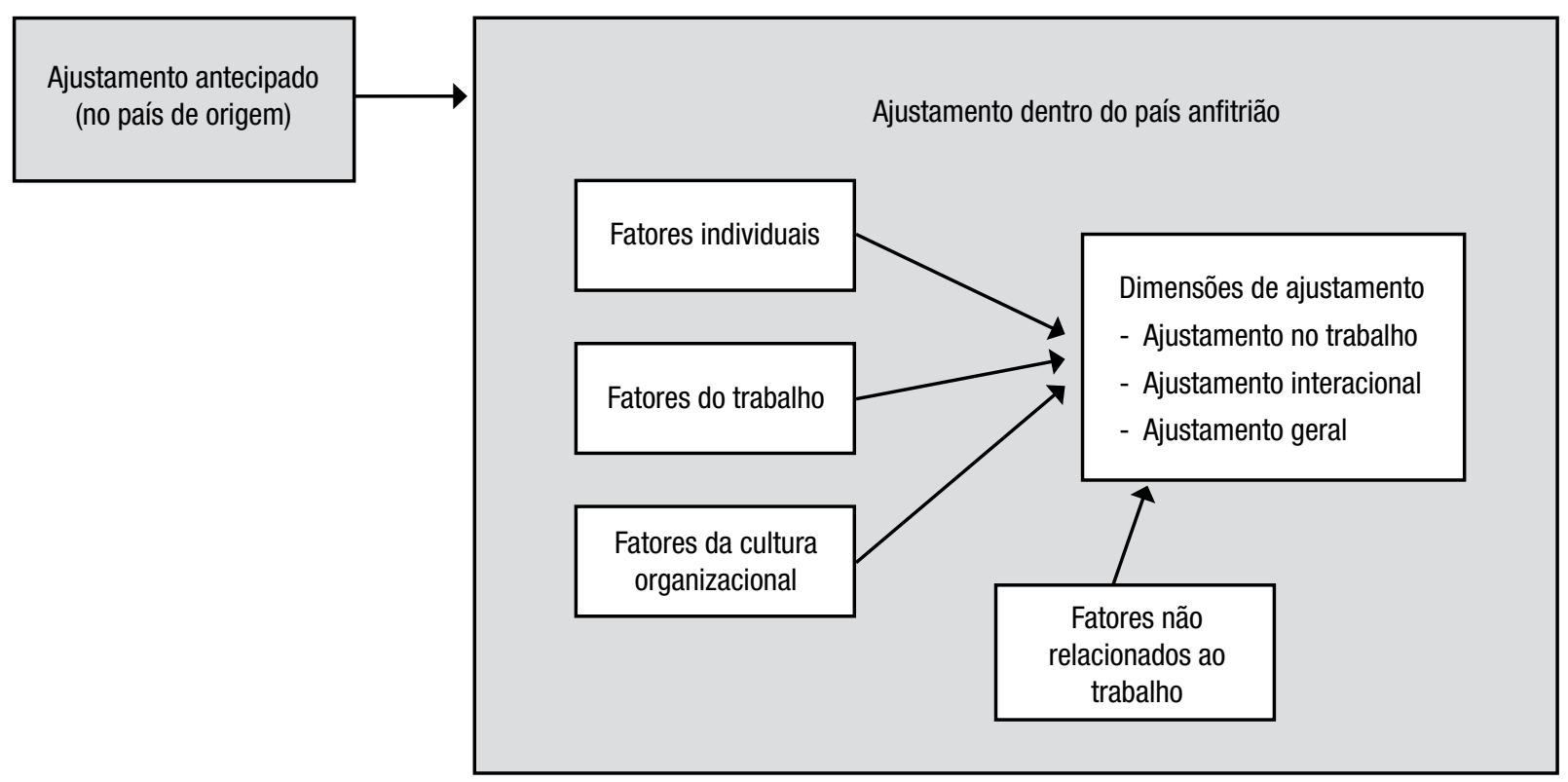


pois, embora citados internacionalmente como casos de sucesso em staffing, devido às menores taxas de falha em expatriação (HARZING, 1995; SANCHEZ, SPECTOR, COOPER, 2000; SCULLION e BREWSTER, 2001; TOH e DENISI, 2005; TUNG, 1982), pouco se sabe sobre seu ajustamento ou os determinantes de seu sucesso.

Ademais, embora sejam considerados casos de sucesso, resultados de pesquisas sugerem que o ajustamento não é uma preocupação nem determinante para o sucesso da expatriação. Em uma pesquisa realizada pela Japan Overseas Enterprises Association, os resultados apontaram que os japoneses parecem se preocupar mais com a administração de pessoal e com as relações de trabalho locais $(64,2 \%)$ do que com o seu ajustamento intercultural no país anfitrião $(24,1 \%)$ (JAPAN..., 2007).

Pesquisas também têm demonstrado que elementos importantes do modelo de Black, Mendenhall e Oddou (1991a), como a novidade cultural, a adaptação do cônjuge e o ajustamento geral, não são determinantes na efetividade dos expatriados japoneses (TUNGLI e PEIPERL, 2009; NICHOLSON e IMAIZUMI, 1993; STEINING E HAMMER, 1992; AMANTE, 1993; WONG, 1996). Como fatores relevantes para a permanência dos expatriados japoneses, esses estudos apontam a cultura nacional e o background cultural (STEINING e HAMMER, 1992); a necessidade do ajustamento cultural entre matriz e subsidiária (WONG, 1996); e o sentimento de lealdade para com a organização, elementos que garantem o comprometimento com a designação ainda no país de origem e privilegiam o ajustamento no trabalho no país anfitrião (AMANTE, 1993).

Vale destacar que o conceito de sucesso em expatriação tem sido objeto de questionamento, dado que o expatriado pode permanecer até o final da designação, mas não ter um bom desempenho. Ademais, a permanência até o final pode resultar em altos custos pessoais, em termos da carreira (especialmente quando a repatriação não é bem feita, por exemplo), estresse ou problemas com a família. Para o expatriado, o sucesso em expatriação tem sido mais associado à possibilidade de desenvolvimento da carreira internacional e à oportunidade de aprendizado em termos de competências interculturais (Stahl e outros, 2009). No entanto, a pesquisa em torno desse tema ainda é escassa e a operacionalização do conceito como a taxa de retorno prematura tem sido a mais utilizada (TUNGLI e PEIPERL, 2009).

O estudo aprofundado do processo de ajustamento dos expatriados japoneses parece ser, portanto, opor- tuno e relevante, como já recomendado por Yamazaki e Kayes (2007), para que seja possível avançar em relação ao modelo de ajustamento internacional de Black, Mendenhall e Oddou (1991a) e colaborar para as políticas de GIP focadas em expatriação, e é essa a contribuição que este artigo pretende fazer.

\section{METODOLOGIA}

Trata-se de um estudo descritivo-analítico, e a abordagem qualitativa de pesquisa foi escolhida porque, segundo Godoy (1995, p. 63), "quando o estudo é de caráter descritivo e o que se busca é o entendimento do fenômeno como um todo, na sua complexidade, é possível que uma análise qualitativa seja a mais indicada". Nesse caso, como a maior parte dos estudos conduzidos sobre o tema até o momento tem sido quantitativa (NICHOLSON e IMAIZUMI, 1993; CALIGIURI, 2000; LEE, 2007; TUNGLI e PEIPERL, 2009), e como o caso dos expatriados japoneses parece ser singular, requerendo, portanto, uma análise mais abrangente e, ao mesmo tempo, mais aprofundada, a abordagem qualitativa parece ser mais adequada.

Conforme mencionado, o objetivo da pesquisa foi investigar como se configura o ajustamento dos expatriados japoneses no Brasil, ou seja, buscou-se levantar as suas percepções (problemas, desafios, pontos positivos/gostos) sobre a sua vivência da expatriação, desde o momento em que souberam que seriam expatriados até a experiência no país anfitrião, com o trabalho e os seus colegas de trabalho, com vida pessoal e a família, e as pessoas do País, de modo geral. O modelo de Black, Mendenhall e Oddou (1991a) foi utilizado como base de fundamentação teórica para a pesquisa e para a construção do roteiro das entrevistas, conforme detalhado adiante.

Como forma de aproximação dos sujeitos da pesquisa, foi contatada a Câmara do Comércio e Indústria Japonesa do Brasil (CCIJB), que forneceu a lista de 40 empresas associadas convidadas a participar, tendo 21 empresas aceitado colaborar com a pesquisa. Elas pertencem a diversos setores de atividade, como automotivo, metalomecânico, eletroeletrônico, têxtil, alimentício, químico, construção civil e serviços. Dentro de cada empresa, todos os expatriados foram convidados para participar da pesquisa, entre os quais 37 aceitaram o convite.

As entrevistas semiestruturadas constituíram o 
método de coleta de dados. O roteiro das entrevistas foi elaborado com base no modelo de Black, Mendenhall e Oddou (1991a), portanto foram formuladas perguntas abertas sobre os fatores que influenciam e os fatores que compõem, após o ajustamento antecipado, as três dimensões do ajustamento no país anfitrião, o ajustamento geral, no trabalho e interacional. A operacionalização das dimensões do ajustamento seguiu o que já foi feito em pesquisas quantitativas anteriores, como Black (1988) e Shaffer, Harrison e Gilley (1999). Um exemplo das perguntas do roteiro é apresentada no Quadro 1 a seguir:

Cada entrevista durou, em média, uma hora e meia. Todas as entrevistas foram realizadas em japonês, pois muitos expatriados não falam português e falam pouco o inglês, e traduzidas e transcritas para o português. Os dados demográficos dos entrevistados estão apresentados na Tabela 1 a seguir. Pode-se observar que a seleção de entrevistados incluiu expatriados com características bem distintas, o que, a princípio, promoveria a obtenção de dados em maior diversidade.

A técnica de análise de dados adotada nesta pesquisa é a análise de conteúdo. Para auxiliar a análise das entrevistas, utilizou-se o software Atlas.ti 5.2 como apoio a três processos: codificação, microanálise dos dados e identificação e validação das categorias. Inicialmente, os segmentos de dados (citações, falas) dos entrevistados foram analisados e codificados. Esses códigos são significados inferidos nos dados e referem-se ao tema ou ideia que a citação represen-

\section{Tabela 1 - Dados demográficos dos entrevistados}

\section{Dados}

\section{N. de expatriados}

Tempo no Brasil:

\begin{tabular}{l|c}
$<1$ ano & 6 \\
$1-3$ anos & 20 \\
$3-5$ anos & 5 \\
$>5$ anos & 6
\end{tabular}

\begin{tabular}{l|c}
\hline Faixa etária: & \\
$20-30$ & 3 \\
$30-40$ & 13 \\
$40-50$ & 11 \\
$>50$ & 10 \\
\hline
\end{tabular}

Família:

Com esposa e filhos $\quad 11$

Somente esposa $\quad 11$

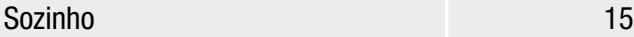

Experiência em expatriação:

Nenhuma

1-3 anos

3-5 anos

$>5$ anos

6

20

5

13

Cargo:

Presidente 9

Diretor $\quad 9$

Assessor diretoria/corporativo 16

Gerente $\quad 2$

\begin{tabular}{l|l} 
Coordenador executivo & 1
\end{tabular}

\section{Quadro 1 - Exemplos de perguntas do roteiro}

Dimensão/fator do modelo de Black, Mendenhall e Oddou (1991a)

Ajustamento antecipado

Ajustamento geral (dentro do país anfitrião)

Ajustamento no trabalho

Ajustamento interacional

Fatores que influenciam 0 ajustamento

\section{Perguntas do roteiro}

- Como o sr. reagiu quando soube que seria expatriado para o Brasil? E a sua família?

- 0 sr. recebeu algum tipo de treinamento antes de vir? De que modo esse treinamento 0 ajudou?

- Do que o sr. gosta/não gosta no país? (vida cotidiana, relações humanas etc.)

- Como é trabalhar com os brasileiros? Que condições facilitam/dificultam 0 seu trabalho?

- Como tem sido a sua experiência em fazer amizade com os brasileiros?

- Como a sua família tem reagido à experiência de morar no Brasil?

- Que tipo de apoio o sr. recebe da sua empresa? 
ta. Posteriormente, esses códigos foram organizados, quantificados e reunidos em torno de categorias. A quantificação na análise de conteúdo é a contagem da frequência de um determinado tema, que pode indicar a importância desse código ou tema em relação aos demais (DELLAGNELO e SILVA, 2005). No caso deste estudo, as frequências foram levantadas pelo software, e as mais significativas são mencionadas na apresentação dos resultados.

\section{APRESENTAÇÃO DOS RESULTADOS}

Com base na análise dos dados, sete categorias foram formadas: ajustamento antecipado, ajustamento geral, ajustamento interacional, ajustamento no trabalho, cultura organizacional, ajustamento da família e sentidos do ajustamento. Como pode ser observado, as categorias formadas correspondem, em grande medi$\mathrm{da}$, às dimensões e fatores do modelo de Black, Mendenhall e Oddou (1991a), o que era esperado, dado que o modelo serviu como base para a elaboração do roteiro de entrevistas.
A análise de conteúdo foi realizada separadamente para os grupos de expatriados sozinhos, com famílias e por cargos, mas não se observaram diferenças significativas para esses casos. Os entrevistados estão identificados como P1, P2, P3 e assim por diante.

As categorias e os temas que as compõem são apresentados no Quadro 2.

\section{Ajustamento antecipado}

No que tange à categoria ajustamento antecipado, três temas foram encontrados: seleção com base em competências técnicas, pouco treinamento intercultural pré-partida e atitude positiva para expatriação. A seleção para a expatriação é baseada, em geral, no critério de competência técnica do trabalho, e não nas competências interculturais, critério recomendado por Black, Mendenhall e Oddou (1991a). Quando notificado pela empresa sobre a missão internacional, o expatriado japonês não questiona a decisão da matriz e aceita de imediato o destino, as condições impostas em termos de benefícios e o tempo da missão. Em geral, a atitude positiva do expatriado japonês diante da designação internacional deve-se apenas

\section{Quadro 2 - Categorias e temas obtidos na análise de conteúdo}

\begin{tabular}{|c|c|}
\hline Categorias & Temas \\
\hline Ajustamento antecipado & $\begin{array}{l}\text { - Seleção com base em competências técnicas } \\
\text { - Pouco treinamento intercultural pré-partida } \\
\text { - Atitude positiva para expatriação }\end{array}$ \\
\hline Ajustamento geral & $\begin{array}{l}\text { - Apreciação da vida em geral no Brasil } \\
\text { - Conveniente ambiente nipônico no Brasil }\end{array}$ \\
\hline Ajustamento interacional & $\begin{array}{l}\text { - Pouco relacionamento com os locais } \\
\text { - Dificuldade de comunicação com os locais }\end{array}$ \\
\hline Ajustamento no trabalho & $\begin{array}{l}\text { - Dificuldade para trabalhar com os locais } \\
\text { - Preocupação em ser aceito pelos locais } \\
\text { - Relevância dos nikkeys } \\
\text { - Aumento da responsabilidade do cargo no Brasil } \\
\text { - Muita pressão e estresse }\end{array}$ \\
\hline Cultura organizacional & $\begin{array}{l}\text { - Necessidade de implantação da cultura da matriz } \\
\text { - Bom apoio organizacional }\end{array}$ \\
\hline Ajustamento da família & $\begin{array}{l}\text { - Dificuldade de comunicação com os locais } \\
\text { - Separação entre vida pessoal e trabalho }\end{array}$ \\
\hline Sentidos de ajustamento & $\begin{array}{l}\text { - Não fazem mudanças pessoais } \\
\text { - Seguir comandos da matriz } \\
\text { - Permanecer até o final da designação }\end{array}$ \\
\hline
\end{tabular}


ao comprometimento com a matriz. Os entrevistados não veem a expatriação como vantajosa em termos do desenvolvimento da carreira, porque relataram que a elite gerencial e a inovação estão na matriz; a expatriação pode significar ficar desalinhado ou desatualizado. Há pouco treinamento intercultural para os candidatos à expatriação, além de esse treinamento ser irregular e o seu conteúdo ser genérico e pouco focado em línguas. Seguem algumas citações representativas do ajustamento antecipado do expatriado japonês no Brasil:

Como é longe... Não sabia nada sobre o Brasil, não sabia se a minha família iria compreender a situação... Mas depois encarei como uma chance e vi de um modo positivo essa missão. (P10)

Eu participei uma vez de um treinamento na empresa e o treinamento também focava em países de língua inglesa... Acho que há partes desse treinamento que foram úteis... (P9)

Não houve nenhuma negociação em termos de benefícios antes de eu vir... Isso é impensável, pois eu sou um empregado... No Japão esse tipo de negociação é impensável. (P6)

\section{Ajustamento geral}

Em relação à categoria ajustamento geral, encontraram-se dois temas, que são a apreciação da vida em geral e o conveniente ambiente nipônico no Brasil. Em relação ao primeiro tema, as falas convergem para dois aspectos positivos, o povo brasileiro e os aspectos relacionados ao País. O povo brasileiro é visto como acolhedor e solidário e, por isso, supõe-se que o expatriado japonês se sinta confortável no Brasil. Os expatriados japoneses não se sentem discriminados e têm facilidade na construção de um relacionamento de confiança com o povo brasileiro, como exemplifica a fala a seguir:

Eu penso que as relações humanas no Brasil são boas, pois não se vê uma discriminação contra orientais e há uma boa impressão sobre os japoneses, há um relacionamento de confiança. (P18)

Em relação aos aspectos do País, há expatriados que apreciam a culinária brasileira, a natureza e o pensamento generalizado de aproveitar a vida (P3;
P14). Ressaltam, também, que há, no Brasil, um ambiente nipônico formado pela sociedade de descendentes de japoneses (nikkey) que facilita a vida do expatriado e de sua família, conforme afirma P19, entre outros:

A influência da sociedade nikkeyé grande. Do ponto de vista particular, há muitos restaurantes, produtos alimentícios, vegetais do Japão. Graças aos nikkeys, não há no Brasil discriminação contra os japoneses, não sinto que haja discriminação, sinto até que os japoneses não são vistos como estrangeiros. Sou grato à sociedade nikkey.

\section{Ajustamento interacional}

Em relação ao ajustamento interacional, a análise encontrou dois temas, que são o pouco relacionamento e a dificuldade de comunicação com locais. A maioria relatou que tem pouco relacionamento com os locais, pois não há oportunidades de interação fora do local de trabalho. Entre aqueles que relataram maior interação e facilidade de comunicação com locais (apenas quatro citações), estão os que praticam esportes como capoeira, futebol e aulas de samba. Muitas vezes, há, até mesmo, a orientação da matriz para que o expatriado mantenha certa distância em relação aos locais, pois a aproximação poderia comprometer a qualidade da gestão. A aproximação é permitida apenas para alavancar negociações e a comunicação com outros parceiros de negócios, conforme afirma P13:

\footnotetext{
No caso da vida privada, há algum intercâmbio, mas não muito... Às vezes sou convidado por fornecedores para ir a alguma churrascaria, casamento, e quando tenho condições participo... Imagine se eu rejeitar todos esses convites e ficar só com os japoneses.. Acho que o trabalho... não fluirá bem... Do outro lado, não significa que devemos ficar no mesmo nível dos locais, curtir com eles, ir beber com os locais, pois nós somos representantes do Japão e ganhamos mais e estamos numa posição superior com responsabilidades, então devemos manter uma certa distância... Esse é um assunto meio delicado... (P13)
}

\section{Ajustamento no trabalho}

Quanto ao ajustamento no trabalho, observou-se a existência de cinco temas principais: dificuldade para trabalhar com os locais, relevância dos nikkeys, 
preocupação em ser aceito pelos locais, aumento da responsabilidade do cargo e muita pressão e estresse. Pode-se afirmar que essa categoria constitui a dimensão central do ajustamento do expatriado japonês no Brasil, pois é a categoria que contempla o maior número de citações, especialmente em relação ao aspecto "dificuldade para trabalhar com os locais", mencionado por quase todos os expatriados.

As dificuldades para trabalhar com os locais são inúmeras, desde diferenças na forma de trabalhar até uma comunicação difícil, dado que muitos dos expatriados não falam português e os brasileiros não falam japonês; e todos, em geral, falam mal o inglês. Quanto à forma de trabalhar, foram apontadas diferenças como a falta de disponibilidade para trabalhar mais horas quando necessário, a falta de planejamento, que resulta em tudo ficar para a "última hora", a falta de assumir a responsabilidade pelos erros, a dificuldade de cumprimento de prazos, a falta de organização e a falta de lógica em alguns procedimentos, que resulta em retrabalho, por parte dos locais.

Nesse contexto, os nikkeys que falam a língua japonesa assumem um relevante papel e são, muitas vezes, promovidos a gerentes ou trabalham como assessores dos expatriados. Além de ajudar na comunicação com os locais, têm o papel de facilitar a supervisão e o controle dos negócios e a difusão da cultura organizacional japonesa. O relato abaixo ilustra o papel deles:

\footnotetext{
A língua utilizada internamente nesta empresa é o inglês, isso porque o japonês não consegue falar logo de imediato a língua. Agora, no departamento de produção, a maior parte dos funcionários é constituída de nikkeys. Os nikkeys trabalham seriamente e também entendem o senso do japonês. A parede entre nikkeys e japoneses é menor que a parede entre nikkeys e os brasileiros não nikkeys. Como a maioria dos funcionários da produção é de nikkeys, torna-se possível comunicar-se em japonês para o trabalho, e isso é uma vantagem. (P19)
}

Observa-se a grande preocupação dos expatriados em serem aceitos pelos locais. Todos, sem exceção, se preocupam em demonstrar esforço e dedicação ao trabalho, em permanecer mais tempo na empresa do que os locais, para que, assim, possam se legitimar na empresa. Um dos relatos (P13) ressalta que eles se sentem "vigiados", pelos locais, quanto às suas folgas, atividades e postura, e sentem que o fato de estarem aqui para contribuir para a gestão da empresa, com um alto salário, implica mais responsabilidades perante os locais.

Um outro dado observado foi que, no Brasil, todos os entrevistados são executivos e, muitas vezes, estão em posições hierárquicas superiores às que ocupavam no Japão, o que significou o aumento do conteúdo do cargo e de suas responsabilidades. Os expatriados são responsáveis, aqui, por mais atribuições, tais como formação e treinamento de equipes, além da comunicação com a matriz. Todos eles se reconhecem como paipu (YAGI, 2009). O paipu é a pronúncia japonesa para pipe (cano), que metaforicamente descreve a atribuição de relatar o que acontece e passar constantemente dados sobre a subsidiária para a matriz no Japão.

A pressão da matriz e as dificuldades no trabalho configuram as principais fontes de estresse e de desânimo para o expatriado japonês no Brasil. A lentidão, as falhas de comunicação, a falta de objetividade e a assimetria de informações geram um sentimento de frustração que se prolonga durante a estadia e, em muitos casos, leva a depressões intermitentes. Por conta dessas dificuldades, muitos se queixam e dizem que o estresse é tão grande que têm vontade de voltar para casa. A atitude em relação ao estresse com o qual se defrontam é a de suportar, a de aguentar até o fim, pois não se sentem à vontade para reclamar com a matriz ou solicitar o retorno prematuro, como demonstra a fala abaixo:

\section{Estou sem a família, estou sozinho aqui, então venho para a empresa e aqui sou um tipo de conselheiro da fábrica [...] e na minha vida particular tudo acontece de modo repetitivo... Eu fico com os outros quatro expatriados do Japão e às vezes alguns deles dizem algo desagradável, e isso cansa, isso vira estresse e aí eu tenho vontade de voltar ao Japão... (P21)}

Para os que estão sem as famílias, a solidão no Brasil leva a um sentimento de nostalgia, que é compensado pelos resultados do trabalho, pois poderão ser usufruídos pela família que está no Japão, conforme relata $\mathrm{P} 6$ :

Toda a minha família está no Japão... Não tenho família aqui e também não tenho como cuidar da minha família... Só espero que eles possam aproveitar os frutos do meu trabalho... É a única coisa que me consola... (P6) 


\section{Cultura organizacional}

A categoria cultura organizacional contemplou dois temas principais, que são a necessidade de implementação da cultura japonesa e o bom apoio organizacional. Em termos de políticas organizacionais, os expatriados japoneses relataram que se ajustam ao que é estritamente necessário no Brasil, tal como a estratégia de vendas e atendimento ao cliente. Os clientes são brasileiros, e as estratégias de vendas, por exemplo, devem ser adequadas ao ambiente local, por isso há um mix da cultura organizacional do Brasil e do Japão, conforme relatou um dos expatriados entrevistados. Na prática, porém, valores e práticas administrativas, tal como tomada de decisão, seguem o modo japonês, e os expatriados japoneses, em geral, esforçam-se para transmitir conhecimentos, know-how e a forma de pensar da matriz para os locais. Não obstante, sentem que a sincronia entre a cultura da matriz e a da subsidiária é difícil de ser alcançada.

\begin{abstract}
A empresa aqui implanta a cultura da matriz do Japão e isso tem gerado estresse em brasileiros e em mim também. Há muitas perguntas por parte da matriz, pois o controle toma como base o modo de gerenciamento do Japão. (P15)
\end{abstract}

Outro fator relevante da cultura organizacional é o apoio organizacional à vida do expatriado no exterior. A empresa se esforça por propiciar conforto (algumas trazem até produtos alimentícios) e segurança para os expatriados, e todos têm a garantia da manutenção de seus empregos quando voltarem ao Japão (emprego vitalício). Isso confere tranquilidade ao expatriado para que se dedique a sua missão no Brasil.

\section{Ajustamento da família}

Dentro da categoria ajustamento da família, o principal tema que emergiu dos relatos foi o das dificuldades da família, sendo a principal delas a comunicação com os locais, muito embora a interação seja restrita e haja dificuldade na mobilidade, pois muitas esposas não dirigem no Brasil, devido à questão da segurança. Aqui, também, a sociedade nikkey aparece como um importante apoio à vida das famílias desses expatriados no Brasil, que resulta em uma "tranquilidade" para os expatriados japoneses se engajarem no trabalho. Vale lembrar que o Brasil é o país que possui a maior colônia japonesa e de seus descendentes do mundo
(MONTOYA, 2011). Além disso, o grande número de expatriados propicia a formação de uma comunidade que ameniza as dificuldades da adaptação e do cotidiano, principalmente das esposas.

Observou-se, também, que os entrevistados procuram separar bem o trabalho e a vida pessoal, não deixando que os problemas familiares interfiram no desempenho do trabalho, conforme relata P10: "Bom, trabalho é trabalho, vida particular é vida particular... Com certeza, surgem problemas no trabalho, mas isso não tem jeito, e eu separo muito bem uma coisa da outra".

\section{Sentidos do ajustamento}

Quanto aos sentidos que atribuem ao ajustamento, três temas surgiram: a crença de que não passam por mudanças pessoais significativas, a necessidade de obedecer aos comandos da matriz e a necessidade de permanecer até o final da designação. Os entrevistados não acreditam que passem, em geral, por mudanças pessoais significativas, a não ser pela necessidade de desenvolver a tolerância e a paciência para lidar com as diferentes formas de trabalhar, a pressão da matriz e o estresse cotidiano. Na verdade, pensam mais no ajustamento organizacional, em seguir os comandos da matriz, a fim de aproximar as culturas entre a subsidiária e a matriz e mitigar os efeitos de um possível choque cultural para os expatriados.

E "ajustar-se" também significa a necessidade de "ficar até o fim". Para o expatriado japonês, desistir da missão internacional é desistir do Japão, pois a cultura da vergonha (BENEDICT, 1946) não permitirá ao expatriado ser aceito novamente na matriz como um membro da organização, e deixar a empresa ainda é algo culturalmente malvisto, como mostram, entre outros, P12 e P8, respectivamente: "Quando você deixa uma empresa e tenta ir para outra, os japoneses sempre acabam pensando que você saiu da outra empresa porque ninguém te queria lá, porque não servia... O japonês pensa assim..." (P12).

Na minha opinião, penso que na cultura do Japão há essa coisa de sair casa e ir para fora lutar. Há esse hábito de que o homem deve sair de casa e a esposa deve proteger o lar... Veja, no século XX houve muitas guerras e o Japão sempre ganhou, mas perdeu a Segunda Grande Guerra... A questão de suportar os desafios e o orgulho fazem parte da cultura do Japão e é para vencer que se vai para 
a guerra. Muito embora não esteja em uma guerra, eu estou batalhando e, se eu fugir, então eu perdi. Quem foge perde e há a mentalidade de que é preferível morrer, suicidar-se, a vergonha de perder é profunda, a cultura da vergonha, a vergonha de fugir do combate... (P8)

A seguir, os resultados obtidos são discutidos no contexto da literatura revisitada.

\section{DISCUSSÃO DOS RESULTADOS}

A análise dos relatos sugere que o expatriado japonês vivencia um dilema, pois, embora tenha facilidades como o suporte operacional para a vida cotidiana, a promessa de emprego vitalício e uma cultura organizacional semelhante à da matriz, à qual já está acostumado, por outro lado, como essa é uma condição temporária, sabe que não deve se aproximar muito dos locais e que não pode voltar para casa antecipadamente, caso não se acostume no país anfitrião, e sabe que a experiência internacional não terá impacto positivo para o desenvolvimento da sua carreira. Portanto, não faz questão de desenvolver as habilidades pessoais do modelo de Black, Mendenhall e Oddou (1991a), ou seja, a autoeficácia, a habilidade de se relacionar com os outros e a habilidade de perceber corretamente o ambiente à sua volta; não faz questão de aprender a língua local ou mesmo de se ajustar ao país em que vive. Dessa maneira, não atinge o ajustamento geral e interacional do modelo de Black, Mendenhall e Oddou (1991a), mas permanece até o final da designação. E, para o expatriado, sucesso na missão internacional significa ficar até o fim e desempenhar o trabalho da forma como a matriz espera. Essa condição organizacional tem respaldo e é reforçada por uma cultura nacional que se reflete, também, nas regras do mercado de trabalho, ou seja, no entendimento de que quem "desiste" não é merecedor de uma nova oportunidade. Portanto, permanecer até o final é a melhor, senão a única, solução possível.

A falta de interesse em torno do ajustamento na vida pessoal, ou seja, em termos do ajustamento geral e interacional, fica evidente quando se observa que, embora declarem gostar do Brasil e do povo brasileiro, os entrevistados demonstraram não fazer esforço para se integrar ao cotidiano e às pessoas do País, a começar pelo fato de que, ainda que alguns estejam morando aqui há algum tempo, não aprenderam o português. Não priorizam a amizade com os locais e preferem a comida japonesa. Esse "insulamento" também foi observado por Nicholson e Imaizumi (1993) e, aqui, é facilitado pela existência de uma grande colônia japonesa.

Com base nos resultados obtidos, uma síntese dos fatores que poderiam promover ou dificultar o ajustamento, de acordo com o modelo de Black, Mendenhall e Oddou (1991a), foi elaborada e é apresentada no Quadro 3.

Há mais fatores dificultadores, em termos organizacionais e individuais, do que facilitadores ao ajustamento intercultural do expatriado japonês no Brasil. No entanto, não parece haver ações das empresas direcionadas a melhorar ou amenizar a situação dos expatriados, a não ser pelo suporte operacional relativo à moradia, carros e medidas ocasionais, como apoio à alimentação, por exemplo. E, embora a recomendação genérica de oferecer aos expatriados treinamentos interculturais apareça na literatura como solução ideal (THOMAS e LAZAROVA, 2006), isso também não acontece.

Com base nos resultados apresentados, é possível analisar o caso dos expatriados japoneses à luz do modelo de Black, Mendenhall e Oddou (1991a). Pode-se dizer que o ajustamento no trabalho para esses expatriados se sobrepõe, em termos de importância, ao ajustamento interacional e geral. Fatores como a força da cultura organizacional da matriz, que inclui desde o apoio organizacional durante a estadia no Brasil até o emprego vitalício na volta ao Japão, e o auxílio dos nikkeys na gestão da subsidiária determinam certo grau de ajustamento no trabalho, que parece suplantar a necessidade de ajustamento interacional e geral. Esses resultados são diferentes dos encontrados por Shay e Baack (2006), por exemplo, que afirmam que, sem o ajustamento geral, não pode haver o ajustamento no trabalho.

Portanto, os resultados sugerem que os fatores que influenciam o ajustamento no modelo de Black, Mendenhall e Oddou (1991a) - novidade cultural, apoio organizacional, características individuais e ajustamento da família - podem ter pesos diferentes quando se analisam pessoas de nacionalidades diferentes. E, embora tenha sido proposto como um modelo universal pela literatura, outros autores também têm apontado limitações em sua aplicabilidade e o etnocentrismo em seus pressupostos, uma vez que foi fortemente fundamentado em pesquisas com ex- 
patriados norte-americanos (FLORKOWSKI e FOGEL, 1999; SCULLION e BREWSTER, 2001).

\section{CONSIDERAÇÕES FINAIS}

Em resposta à pergunta desta pesquisa, pode-se dizer, de início, que o expatriado japonês não se ajusta, mas convive. O ajustamento geral e o ajustamento interacional não são priorizados, por não serem tão relevantes quanto o trabalho. Mesmo sem ajustar-se no trabalho, devido ao estresse oriundo das diferenças culturais do trabalho em relação aos locais, o trabalho é obrigação e tem que ser feito em qualquer lugar.

A efetividade do expatriado japonês repousa na sua preocupação em se ajustar não com o ambiente local, mas com as expectativas da matriz quanto à permanência no país hospedeiro e término da missão. O que determina a efetividade do desempenho do expatriado japonês não está relacionado ao ajuste ao ambiente brasileiro, mas, sim, a fatores culturais relacionados ao Japão, como a obrigação em demonstrar lealdade à empresa. Desistir da missão no Brasil é o mesmo que desistir do Japão, envergonhando a empresa e a si próprio perante a matriz. Em vez de passar por isso, é preferível tolerar as dificuldades até o fim.

Assim, o estudo dos expatriados japoneses contribui para a literatura sobre expatriação e ajustamento, no sentido de destacar a importância da nacionalidade e background cultural do expatriado e do fator apoio organizacional, que reflete a responsabilidade da organização perante a efetividade do expatriado em sua missão. Os resultados também sugerem que as dimensões e fatores do ajustamento do modelo de Black, Mendenhall e Oddou (1991a) podem ter pesos diferentes para as diferentes nacionalidades e que, além disso, comprometimento e desempenho no trabalho não estão necessariamente correlacionados com ajustamento e satisfação com a missão.

Também contribui para reforçar a necessidade do questionamento do conceito do sucesso em expatriação, ao apontar que os expatriados japoneses adotam a perspectiva organizacional para a sua definição pessoal de sucesso para a missão, ou seja, diferentemente de outros expatriados, que veem a carreira internacional como uma oportunidade de aprendizado em termos de competências interculturais

\section{Quadro 3 - Fatores facilitadores e dificultadores do ajustamento do expatriado japonês no Brasil}

\begin{tabular}{|c|c|c|}
\hline $\begin{array}{l}\text { Fatores que influenciam } \\
\qquad 0 \text { ajustamento }\end{array}$ & Facilitadores & Dificultadores \\
\hline Individuais & $\begin{array}{l}\text { - Alto grau de autocontrole, que ajuda a lidar com } \\
\text { o estresse; }\end{array}$ & $\begin{array}{l}\text { - Baixo grau de autoeficácia, não se preocupa em } \\
\text { aprender novos comportamentos; } \\
\text { - Baixo grau de habilidade de relacionamento; } \\
\text { - Baixo grau de habilidade de percepção, pois tende } \\
\text { a perceber o ambiente local com valores japoneses; }\end{array}$ \\
\hline Relacionados ao trabalho & $\begin{array}{l}\text { - Alta clareza da função exercida; } \\
\text { - Suporte dos nikkeys; }\end{array}$ & $\begin{array}{l}\text { - Restrita autonomia na função, alinhamento cons- } \\
\text { tante com a matriz; } \\
\text { - Novidade da função, aumento do conteúdo e res- } \\
\text { ponsabilidade do cargo; } \\
\text { - Alto grau de conflito na função (entre subsidiária e } \\
\text { matriz, principalmente); } \\
\text { - Muitas diferenças na forma de trabalhar em relação } \\
\text { aos brasileiros; }\end{array}$ \\
\hline Cultura organizacional & $\begin{array}{l}\text { - Apoio logístico da empresa para moradia e } \\
\text { importação de produtos japoneses; } \\
\text { - Cultura organizacional, por imposição, seme- } \\
\text { Ihante à da matriz, que "neutraliza" efeitos da } \\
\text { novidade da cultura organizacional da subsidiária; }\end{array}$ & - Pouco treinamento intercultural; \\
\hline $\begin{array}{l}\text { Não relacionados ao } \\
\text { trabalho }\end{array}$ & $\begin{array}{l}\text { - Ambiente brasileiro percebido como favorável; } \\
\text { - Sociedade nikkey, que ajuda a família, inclusive. }\end{array}$ & $\begin{array}{l}\text { - Comunidade japonesa, que, ao mesmo tempo que } \\
\text { ajuda, acaba segregando. }\end{array}$ \\
\hline
\end{tabular}


e de desenvolvimento (STAHL e outros, 2009), para os japoneses, a expatriação é vista apenas como um dever para com a organização e um modo de prover a família; portanto, o sucesso é desempenhar bem o trabalho e permanecer até o fim, não importando a que custo, em termos de sofrimento e estresse pessoal.

Em termos de limitações da análise, a seleção de entrevistados poderia ter contemplado funcionários brasileiros, nikkeys ou não, que lidassem diretamente com os expatriados, para aprofundar a análise do seu comportamento em missão internacional. Seria interessante a inclusão de expatriados do sexo feminino, para verificar se há diferenças no ajustamento dentro do país anfitrião.

Como pesquisas futuras, sugere-se aprofundar $\mathrm{O}$ estudo sobre o ajustamento em outros contextos e com expatriados de outras nacionalidades que não a norte-americana, para se verificar se o caso dos japoneses é único ou se haveria outros casos de expatriados em que o ajustamento não seria tão importante para o bom desempenho. Sugere-se, também, que as pesquisas se estendam aos colegas de trabalho locais, para se verificarem as percepções sobre o desempenho dos expatriados, que dariam outra perspectiva, inclusive, sobre o tema do sucesso na expatriação.

\section{REFERÊNCIAS}

AMANTE, M. S. V. Tensions in industrial democracy and human resource management: a case study of Japanese enterprises in the Philippines. The International Journal of Human Resource Management, v. 4, n. 1, p. 129-158, 1993.

ANDREASON, A. W. Expatriate adjustment to foreign assignments. International Journal of Commerce \& Management, v. 13, n. 1, p. 42-60, 2003.

AYCAN, Z. Expatriate adjustment as a multifaceted phenomenon: individual and organizational level predictors. The International Journal of Human Resource Management, v. 8, n. 4, p. 434-455, 1997.

BENEDICT, R. The Chrysanthemus and the sword. 5th ed. Tokyo: Tuttle, 1946. 273 p.

BLACK, J. S. Work role transitions: a study of American expatriate managers in Japan. Journal of International Business Studies, v. 19, n. 2, p. 277-294, 1988.
BLACK, J. S; MENDENHALL, M; ODDOU, G. Toward a comprehensive model of international adjustment: an integration of multiple theoretical perspectives. Academy of Management Review, v. 16, n. 2, p. 291-317, 1991a.

BLACK, J. S; MENDENHALL, M; ODDOU, G. The U-curve adjustment hypothesis revisited: a review and theoretical framework. Journal of International Business Studies, v. 22, n. 2, p. 225-247, 1991 b.

BJORKMAN, I; STAHL, G. International human resource management research: an introduction to the field. In: BJORKMAN, I; STAHL, G. (Coords) Handbook of research in international buman resource management. Cheltenham: Edward Elgar, 2006. p. 1-11.

CALIGIURI, P. M. Selecting expatriates for personality characteristics: a moderating effect of personality between host national contact and cross-cultural adjustment. $\mathrm{Ma}$ nagement International Review, v. 40, n. 1, p. 61-80, 2000.

DELLAGNELO, E; SILVA, R. Análise de conteúdo e sua aplicação em pesquisa na administração. In: VIEIRA, M. M. F; ZOUAIN, D. M. (Orgs) Pesquisa qualitativa em administração: teoria e prática. Rio de Janeiro: FGV, 2005. 240 p.

FLORKOWSKI, G. W; FOGEL, D. S. Expatriate adjustment and commitment: the role of host-unit treatment. International Journal of Human Resource Management, v. 19, n. 5, p. 783-807, 1999.

GODOY, A. S. Introdução à pesquisa qualitativa e suas possibilidades. RAE-Revista de Administração de Empresas, v. 35, n. 2, p. 57-63, 1995.

HARRISON, D. A; SHAFFER, M. A. Mapping the criterion space for expatriate success: task-based, relationship-based performance, effort \& adaptation. International Journal of Human Resource Management, v. 16, n. 8, p. 1454-1474, 2005.

HARZING, A. W. K. The persistent myth of high expatriate failure rates. The International Journal of Human Resource Management, v. 6, n. 2, p. 457-474, 1995.

HOMEM, I. D; TOLFO, S. R. Práticas de gestão internacional de pessoas: compensação e seleção de expatriados em uma multinacional brasileira. RAC-Eletrônica, v. 1, n. 2, 2008. Disponível em: http://www.anpad.org.br/periodicos/ arq_pdf/a_734.pdf. Acesso em 15.09.2008. 
JAPAN OVERSEAS ENTERPRISES ASSOCIATION. Kaigaihakensha handobuko: keikenshaga kataru shokuba komiunitinojitsuyou nouhau. Tokyo: Chunanbei, 2007. 173 p.

LEE, H. W. Factors that influence expatriate failure: an interview study. International Journal of Management, v. 24, n. 3, p. 403-413, 2007.

MONTOYA,W. G. Maior colônia japonesa do mundo se une em SP após tragédia. Exame.com, v. 1, n. 988, 2011. Disponível em: http://exame.abril.com.br/brasil/noticias/maior-colonia-japonesa-do-mundo-se-une-em-sp-apos-tragedia. Acesso em 25.07.2011.

NICHOLSON, N; IMAIZUMI, A. The adjustment of Japanese expatriates to living and working in Britain. British Journal of Management, v. 4, n. 2, p. 119-134, 1993.

OBERG, K. Cultural shock: adjustment to new cultural environments. Practical Anthropology, v. 7, n. 1, p. 177-182, 1960.

SANCHEZ, J. I; SPECTOR, P. E; COOPER, C. L. Adapting to a boundaryless world: a developmental expatriate model. Academy of Management Executive, v. 14, n. 2, p. 96-106, 2000.

SCULLION, H; BREWSTER, C. The management of expatriates: messages from Europe. Journal of World Business, v. 36, n. 4, p. 346-365, 2001.

SHAFFER, M. A; HARRISON, D. A; GILLEY, K. M. Dimensions, determinants, and differences in the expatriate adjustment process. Journal of International Business Studies, v. 30, n. 3, p. 557-581, 1999.

SHAY, J. P; BAACK, S. An empirical investigation of the relationships between modes and degree of expatriate adjustment and multiple measures of performance. International Journal of Cross Cultural Management, v. 6, n. 3, p. 275-294, 2006.

STAHL, G. K; CALIGIURI, P. The effectiveness of expatriate coping strategies: the moderating role of cultural distance, position level, and time on the international assignment. Journal of Applied Psychology, v. 90, n. 4, p. 603-615, 2005.

STAHL, G. K; CHUA, C; CALIGIURI, P; CERDIN, J; TANIGU$\mathrm{CHI}, \mathrm{M}$. Predictors of turnover intentions in learning-driven and demand-driven international assignments: the role of repatriation concerns, satisfaction with company support and perceived career advancement opportunities. Human Resource Management, v. 48, n. 1, p. 89-109, 2009.

STEINING, B. W; HAMMER, M. R. Cultural baggage and the adaptation of expatriate American and Japanese managers. Management International Review, v. 32, n. 1, p. 77-89, 1992.

STROH, L. K; DENNIS, L. E; CRAMER, T. C. Predictors of expatriate adjustment. The International Journal of Organizational Analysis, v. 2, n. 2, p. 176-192, 1994.

THOMAS, D. C; LAZAROVA, M. B. Expatriate adjustment and performance: a critical review. In: BJORKMAN, I; STAHL, G. (Coords) Handbook of research in international human resource management. Cheltenham: Edward Elgar, 2006. p. $247-264$.

TOH, S. M; DENISI, A.S. A local perspective to expatriate success. Academy of Management Executive, v. 19, n. 1, p. 132-146, 2005.

TUNG, R. L. Selection and training procedures of U.S, European, and Japanese multinationals. California Management Review, v. 25, n. 1, p. 57-71, 1982.

TUNG, R. L. Expatriate assignments: enhancing success and minimizing failure. Academy of Management Executive, v. 1, n. 2, p. 117-126, 1987.

TUNGLI, Z; PEIPERL, M. Expatriate practices in German, Japanese, U.K, and U.S. multinational companies: a comparative survey of changes. Human Resource Management, $\mathrm{v}$. 48, n. 1, p. 153-171, 2009.

WINKELMAN, M. Cultural shock and adaptation. Journal of Counseling \& Development, v. 73, n. 2, p. 121-126, 1994.

WONG, M. M. L. Managing organizational culture in a Japanese organization in Hong Kong. The International Executive, v. 38, n. 6, p. 807-824, 1996.

YAGI, N. An ethnographic perspective on boundary spanning in a binational organization. In: EUROPEAN GROUP OF ORGANIZATION STUDIES, 25, 2009, Barcelona. Anais. Barcelona: EGOS, 2009.

YAMAZAKI, Y; KAYES, D. C. Expatriate learning: exploring how Japanese managers adapt in the United States. The International Journal of Human Resource Management, v. 18, n. 8, p. 1373-1395, 2007. 